\title{
Influence of social distance toward individuals with psychotic disorders by medical background
}

\author{
Chiong-Hee Wong ${ }^{1}$, Shih-Chao Chien ${ }^{1}$, Yi-Hong Zeng ${ }^{2,3,4}$, Chien-Chiu Huang ${ }^{4,5}$, Weide Tsai ${ }^{1,3}$, \\ Chien-Wei Chen ${ }^{6,7,}$, Yu-Jang Su ${ }^{1,3,9,10}$, Wen-Han Chang ${ }^{1,3,9,11,12,13}$, Pang-Yen Chen ${ }^{1,4,10}$ ^
}

${ }^{1}$ Department of Emergency Medicine, Mackay Memorial Hospital, Taipei, Taiwan; ${ }^{2}$ Division of Endocrinology and Metabolism, Department of Internal Medicine, MacKay Memorial Hospital, Taipei, Taiwan; ${ }^{3}$ Department of Medicine, MacKay Medical College, New Taipei City, Taiwan; ${ }^{4}$ Institute of Public Health, National Yang Ming Chiao Tung University College of Medicine, Taipei, Taiwan; ${ }^{5}$ Sui-An Rehabilitation Clinic, Taipei, Taiwan; ${ }^{6}$ Department of Diagnostic Radiology, Chang Gung Memorial Hospital Chiayi Branch, Chiayi, Taiwan; ${ }^{7}$ College of Medicine, Chang Gung University, Taoyuan, Taiwan; ${ }^{8}$ Institute of Medicine, Chung Shan Medical University, Taichung, Taiwan; ${ }^{9}$ Mackay Junior College of Medicine, Nursing, and Management, Taipei, Taiwan; ${ }^{10}$ Department of Nursing, Yuanpei University of Medical Technology, Hsinchu, Taiwan; ${ }^{11}$ Graduate Institute of Injury Prevention and Control, Taipei Medical University, Taipei, Taiwan; ${ }^{12}$ Institute of Mechatronic Engineering, National Taipei University of Technology, Taipei, Taiwan; ${ }^{13}$ Department of Emergency Medicine, School of Medicine, Taipei Medical University, Taipei, Taiwan Contributions: (I) Conception and design: WH Chang, PY Chen; (II) Administrative support: W Tsai; (III) Provision of study materials or patients: CW Chen, YJ Su; (IV) Collection and assembly of data: YH Zeng, CC Huang; (V) Data analysis and interpretation: CH Wong, SC Chien; (VI) Manuscript writing: All authors; (VII) Final approval of manuscript: All authors.

Correspondence to: Pang-Yen Chen. No. 92, Sec. 2, Chung Shan North Rd., Taipei 10449, Taiwan. Email: pongyen2000@gmail.com.

Background: Discrimination of mental illness has formed obstacles to the development of the public health system. More and more evidence shows that many psychiatric patients say that much discrimination in life comes from the medical system. Medical caregivers may also exhibit a discriminatory attitude, resulting in a decline in the quality of medical care. Many studies explored whether medical staff has a different attitude towards the mentally ill from the general public. However, the medical staff's working years and their social distance to mental illness patients are still unclear and rare. The cross-sectional study aimed to analyze the association of social distancing and the working seniority of health professionals.

Methods: A cross-sectional study design was applied with convenience sampling. The proper research was conducted from May 13, 2020, to May 31, 2020 by an internet-based questionnaire. We use exploratory factor analysis to measure the convergent validity and calculate Cronbach's $\alpha$ value to measure the reliability. We used a two-sample t-test and one-way analysis of variance (ANOVA) to perform univariate analysis. Multiple regression analysis was conducted with the independent variables significant in univariate analysis, and the social distancing average score was the dependent variable.

Results: There were 216 valid questionnaires. The response rate was $57.75 \%$. The junior group comprised 105 participants and the senior group 111 ones, with the majority being female (80\%). The senior group's average age was 43.01 ( $\mathrm{SD}=5.109$ ), significantly higher than 31.08 ( $\mathrm{SD}=6.159$ ) in the junior group. The Cronbach's $\alpha$ value was 0.915 that showed relatively good reliability. The descriptive analyses of social distancing scores in two working seniority groups demonstrated average total scores of 16.67 in the senior group, 18.87 in the junior group. There was a significantly negative association between age and social distancing score. The master's degree and/or doctor degree group and the bachelor's degree group were considerably higher than those of the senior high school degree group. Gender and marital status had no statistical significance in the multiple regression analysis.

Conclusions: Healthcare professionals with a shorter career time were shown to have a relatively favorable attitude toward mentally ill people. Multiple regression analysis suggested that attitudes to mental illness among the health care provider were positively associated with younger age and higher education levels.

$\wedge$ ORCID: 0000-0002-5933-5820. 
It was recommended that a good social contact experience with the patient, such as work and psychiatry training, is compelling. It implied that a systemic education program for caring for psychiatric patients is necessary for Taiwan's health care institutions.

Keywords: Social distancing; health professional; attitudes to mental illness; health professionals continuing education

Received: 28 January 2021; Accepted: 09 March 2021; Published: 30 November 2021. doi: $10.21037 /$ ht-21-5

View this article at: https://dx.doi.org/10.21037/ht-21-5

\section{Introduction}

Discrimination and prejudice against people with mental health conditions have always been an essential issue in the world's medical system, which formed obstacles to developing the public health system (1-3). Social discrimination also reduces the quality of life of people with mental health conditions $(4,5)$. Achieving de-smeared labels has become a goal of various medical institutions and organizations worldwide (6). To improve this problem, the World Psychiatric Association (WPA) launched the "Open the doors" program in 1996 to combat mental illness, prejudice, and stigmatization (7). At present, the general public's attitude towards people with mental health conditions is not apparent. It showed positive (8-10), negative (11), and neutral (12) in different researches.

More and more evidence shows that many psychiatric patients say that a large part of the discrimination in life comes from the medical system $(13,14)$. Medical caregivers may also exhibit a discriminatory attitude, resulting in a decline in medical care quality (15). Discrimination of people with a mental health condition in the medical system will affect the treatment and care they receive, thereby delaying their recovery $(15,16)$. The stigmatization of mental illness in the medical system may cause low-quality medical care, mislabeled diagnosis, excessive pessimism about the treatment result, only focus on drug use, insufficient explanation of informed consent, more treatment side effects, and neglect of patient needs (17-19). These consequences will lead patients to seek medical assistance more passively (20), increase the chance of suicide (21), increase the mortality and comorbidity of patients (15).

The theme of this research project is to understand the social distance and attitude to mentally ill patients of the general public relative to medical staff. Longer working years and medical ethics education have shown in previous literature that it can effectively reduce discrimination against people with a mental health condition (22-27). In 2003, Turkish research on teaching hospitals showed that the hospital's ordinary staff, compared with medical care, have the best patience and attitude. However, they do not have an excellent medical professional background (28). Medical staff is more likely to show impatient negative emotions for people with a mental health condition. This part can be improved in future medical education. According to the previous research results of Acta Psychiatr Scand in 2007, medical practitioners have a higher education level, a younger age, and most live in the suburbs relative to the family members of people with a mental health condition and the general public (29). Compared with the general public and the families of patients, medical practitioners have a relatively friendly attitude towards people with a mental health condition, which can be attributed to a better understanding of the disease and a higher degree of academic awareness. These could be the cornerstone of the text plan theory.

This study is based on the previous research results. It is aimed at whether the social distance between medical staff and people with mental health conditions changes due to working years. We present the following article following the STROBE reporting checklist (available at https://dx.doi. org/10.21037/ht-21-5).

\section{Methods}

\section{Participants and procedure}

The present study was approved by the Joint Institutional Review Board (JIRB) of the Mackay Memorial Hospital (IRB numbers: 21MMHIS026e). The study was conducted in accordance with the Declaration of Helsinki (as revised in 2013).

The study aimed to analyze the association of social distancing and the working seniority of health professionals. 
A cross-sectional study design was applied with convenience sampling. The study population comprised the related community groups of our team members on the LINE app that included the emergency department, the endocrine department of Mackay Memorial Hospital, two rehabilitation clinics in New Taipei city, and two rehabilitation clinics in Tainan city. The LINE app community groups were composed of colleagues of our team members that were all health professionals.

The pilot study was carried out in May 6, 2020 to May 13, 2020. We used a traditional paper-based questionnaire, and the participants were also the colleagues of our team members. Fourteen questionnaires were collected to perform item analysis. The participants in the pilot study were not permitted to participate in the formal investigation. The proper research was conducted from May 13, 2020, to May 31, 2020. We used an internet-based questionnaire by Google Sheets and carried the short URL in the LINE app group to voluntarily participate in the study. For protecting participants' voluntariness and privacy and the scruple about the problem of unequal power in the workplace, the traditional paper-based way was abandoned. Google Sheets adopted the web-based anonymous questionnaire, and we carried the short URL in the LINE group so that the group members could voluntarily participate in the study. An explicit explanation was presented on the first page of the questionnaire. Entrance to the following pages was permitted after signing informed consent.

The inclusion criteria of participants were the qualification of health professionals. Questionnaires from those who do not meet the inclusion criteria or the primary independent variable (the working seniority) that could not be determined were excluded. Initially, 251 questionnaires were collected, among which 34 questionnaires were removed due to the eligibility problem, and one questionnaire was removed due to the apparent error in replying to the working seniority.

\section{Measurements}

The dependent factor construction in the questionnaire was composed of 7 items. According to the results of item analysis in the pilot study, we should delete 1 item by way of reliability analysis and three using factor analysis. Owing to the few questionnaires (only 14), we decide to use all seven formal study items.

The participants were required to rate items on a 5 -point Likert scale ranging from " $1=$ strongly unwilling" to " $5=$ strongly willing". Due to our questionnaire's high reliability, the average score was adopted to be the dependent variable. The independent variables included the working seniority and general socio-demographic characteristics, such as gender, age, marital status, and education level. Association between working types of health professionals and social distancing was also our study objectives, so we included it in the independent variables. We brought the variable "family or close friends diagnosed with mental illness" in our independent variables from reviewing the previous study results.

\section{Statistical analysis}

Descriptive analyses were performed for socio-demographic and other independent variables. Continuous variables were listed as mean and standard deviation (SD); they were shown as frequency and percentage for categorical variables. We use exploratory factor analysis to measure the convergent validity and calculate Cronbach's alpha value to measure the reliability.

We used a two-sample $t$-test and one-way analysis of variance (ANOVA) to perform univariate analysis. Multiple regression analysis was conducted with the independent variables significant in univariate analysis results, and social distancing average score is the dependent variable. All were performed using SPSS 24 version. A two-sided $\mathrm{P}$ value below 0.05 was considered statistically significant.

\section{Results}

There were 216 valid questionnaires. The response rate was $57.75 \%$. Table 1 showed the descriptive analyses of socio-demographic and other independent variables in two different working seniority groups categorized by the median in all samples. The junior group comprised 105 participants and the senior group 111 ones, with the majority being female (80\%). The senior group's average age was 43.01 ( $\mathrm{SD}=5.109)$, significantly higher than 31.08 $(\mathrm{SD}=6.159)$ in the junior group. The proportion of being married in the senior group $(81.1 \%)$ was substantially higher than the junior group (42.9\%). In education level and working type, the majority in both groups was bachelor degree and nurse. There was no significant difference in both groups concerning family or close friends diagnosed with mental illness.

Table 2 presented the reliability and validity of the questionnaire. The eigenvalue of the extracted factor was 
Table 1 General characteristics of participants

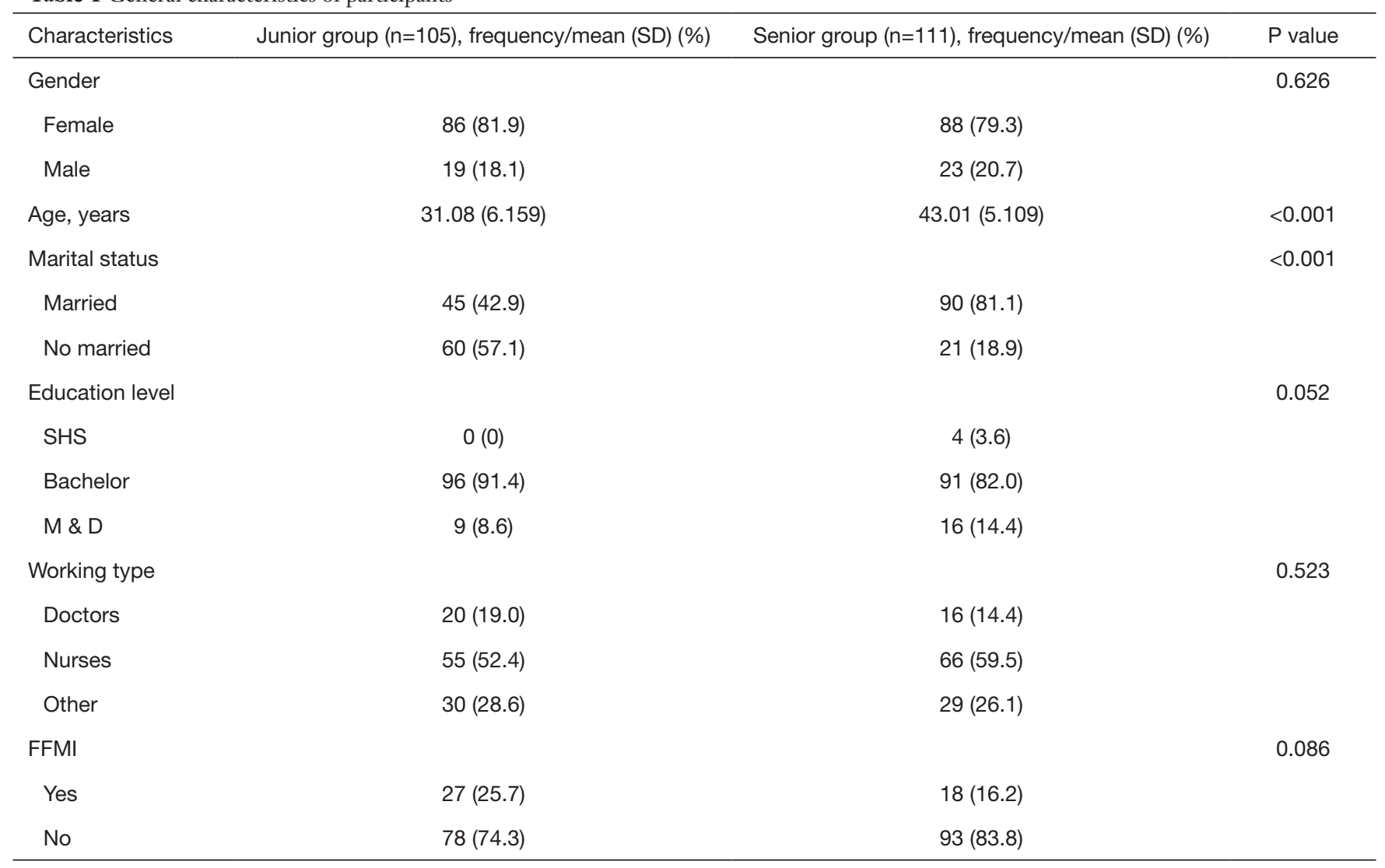

SHS, senior high school degree; M \& D, master degree and/or doctor degree; FFMI, family or close friends diagnosed with mental illness.

Table 2 Validity and reliability of social distancing

\begin{tabular}{lcccc}
\hline \multirow{2}{*}{ Factor } & Construction content & Factor loadings & \multicolumn{2}{c}{ Extraction sums of squared loadings } \\
\cline { 3 - 4 } Social distancing & No. 2 & 0.872 & Eigenvalues & Cumulative \% \\
& No. 1 & 0.845 & 4.651 & 66.442 \\
& No. 4 & 0.840 & \\
No. 3 & 0.818 & \\
No. 6 & 0.795 & \\
No. 7 & 0.765 & \\
No. 5 & 0.763 & \\
\hline
\end{tabular}

No., number.

4.651. The factor loadings of all seven items were more significant than 0.76 , and the cumulative explained variation was $66.44 \%$. These results showed moderately satisfied convergent validity. The Cronbach's $\alpha$ value was 0.915 that showed relatively good reliability. The descriptive analyses of social distancing scores in two working seniority groups were presented in Table 3, which demonstrated average total scores of 16.67 in the senior group, 18.87 in the junior 
Table 3 Social distancing scores of different age groups

\begin{tabular}{lcccccc}
\hline \multirow{2}{*}{ Levels } & \multicolumn{2}{c}{ Junior group } & & \multicolumn{2}{c}{ Senior group } & \\
\cline { 2 - 3 } & Mean & SD & & Mean & SD & \\
\hline No. 1 & 3.17 & 0.935 & & 2.87 & 0.964 & $1-5$ \\
No. 2 & 2.74 & 1.056 & & 2.36 & 0.998 & $1-5$ \\
No. 3 & 3.22 & 0.971 & & 2.96 & 0.972 & $1-5$ \\
No. 4 & 2.50 & 1.057 & & 2.16 & 1.049 & $1-5$ \\
No. 5 & 3.35 & 1.074 & & 2.91 & 1.041 & $1-5$ \\
No. 6 & 2.05 & 0.934 & & 1.78 & 0.967 & $1-5$ \\
No. 7 & 1.84 & 0.942 & & 1.61 & 0.936 & $1-5$ \\
Total & 18.87 & 5.630 & 16.67 & 5.624 & $7-35$ \\
score & & & & & \\
\hline
\end{tabular}

No., number.

Table 4 Univariate analysis of socio-demographic characteristics

\begin{tabular}{lcc}
\hline Independent variables & $\begin{array}{c}\text { Social distancing } \\
\text { scores }\end{array}$ & Post hoc \\
\hline Working seniority & $2.872^{\star *}$ & $13-34<0-12$ \\
Gender & 1.236 & - \\
Age & $5.672^{\star \star *}$ & $40-49<20-29$ \\
Marital status & $-2.241^{\star}$ & Married $<$ No married \\
Education level & $3.382^{*}$ & SHS $<$ M \& D \\
Working type & 1.261 & - \\
FFMI & 0.122 & - \\
\hline
\end{tabular}

*, $\mathrm{P} \leq 0.05 ;{ }^{* \star}, \mathrm{P} \leq 0.01 ;{ }^{* \star}, \mathrm{P} \leq 0.001$. SHS, senior high school degree; $M$ \& D, master degree and/or doctor degree; FFMI, family or close friends diagnosed with mental illness.

group.

The results of the univariate analysis in Table 4 revealed the scores of the junior group significantly higher than the senior group $(\mathrm{P} \leq 0.01)$, the $20-29$ years old group substantially higher than $40-49$ years old group $(\mathrm{P} \leq 0.001)$, the never-married group considerably higher than the married group $(\mathrm{P} \leq 0.05)$, the master degree and/or doctor degree group markedly more elevated than the senior high school degree group $(\mathrm{P} \leq 0.05)$. There was no significant difference in working type groups and family or close friends diagnosed with mental illness groups.

The result of multiple regression analysis in Table 5 suggested no significant difference in the working seniority groups after controlling for gender, age, marital status,
Table 5 Correlates of social distancing scores and general characteristics

\begin{tabular}{lccc}
\hline \multirow{2}{*}{ Characteristics } & \multicolumn{3}{c}{ Social distancing scores } \\
\cline { 2 - 4 } Working seniority & & $95 \% \mathrm{Cl}$ & $\mathrm{P}$ \\
Senior group & 0.132 & -0.177 to 0.441 & 0.401 \\
Junior group & Ref. & & \\
Gender & & & \\
Male & -0.231 & -0.509 to 0.048 & 0.104 \\
Female & Ref. & & \\
Age & -0.037 & & \\
Marital status & & & \\
Married & -0.002 & -0.267 to 0.263 & 0.990 \\
No married & Ref. & & \\
Education level & & & 0.012 \\
M \& D & 1.082 & 0.241 to 1.922 & 0.050 \\
Bachelor & 0.785 & 0.001 to 1.569 & \\
SHS & Ref. & & \\
R square & & & \\
\hline
\end{tabular}

SHS, senior high school degree; M \& D, master degree and/ or doctor degree; FFMI, family or close friends diagnosed with mental illness; Ref, reference group.

and education level. There was a significantly negative association between age and social distancing score. The master's degree and/or doctor degree group and the bachelor's degree group were considerably higher than those of the senior high school degree group. Gender and marital status had no statistical significance in the multiple regression analysis. The $\mathrm{R}$ square was 0.126 and adjusted $\mathrm{R}$ square 0.101 .

\section{Discussion}

Compared to the senior staff (working years $\geq 13$ years), junior staff (working years $<13$ years) had significantly more positive attitudes to social distance. In the multiple regression model, younger age and higher education level had the less social distance, but working years showed no statistical significance.

In the present study, senior staff had more negative attitudes to mental illness compared to junior staff. We hypothesized that the health care provider with a longer 
length of service is like a professional job, and our results are consistent with the previous study. The professionals' possible explanation is too busy to have enough time to communicate with mental illness people. However, the mechanism needs further research to be confirmed.

The factor that having "family or close friends diagnosed with mental illness" was negatively correlated with "social distancing" among the professionals. Social contact is one of the most effective interventions to reduce mental health-related stigma and discrimination among adults (30). This phenomenon was not observed in our study. The possible explanation is the definite social contact between the participant and his family or close friends with mental illness related to cultural differences. More "social distancing" towards mental illness people was observed in health care providers who have marriage compared with those who were never married. One reasonable explanation is that parents would worry about their children's safety and hence had negative attitudes towards the social distance. More studies are needed to confirm the relationship and explore the potential explanations. Other factors like gender and occupation/specialty did not affect the social distance among health care providers.

Medical staff's discriminatory attitude towards people with a mental health condition will result in further social marginalization of patients (31). As ordinary people, professional medical staff sometimes show a negative attitude towards people with mental illness. This problem affects the quality of medical care to a considerable extent. In addition, the prejudice of psychiatric patients will further reduce the willingness of new medical students to enter the psychiatric department, which will cause a shortage of psychiatric workforce and a problem of reduced quality of care (32). Over the years, psychiatrists have faced a lack of human resources $(33,34)$. Under the influence of these conditions, discrimination against mentally ill patients in the medical system has slowly become a public health crisis.

As mentioned in the previous literature, medical professionals have an apparent positive attitude towards mentally ill patients, fewer "social restrictions" and prejudice towards patients, and more tolerance (35-38). According to a 2017 study in Singapore, medical professionals generally have a more positive attitude towards people with mental illness than the general public, but their "social distancing" is no different from that of the average person (23). Medical professionals are not more willing to get close to people with mental illness than ordinary people. Compared with doctors, nurses have a more negative attitude towards people with mental health conditions. If the ethnicity is Chinese, or those with a lower education level, they have a more negative attitude towards mental illness. Reflecting the "not in my back yard" phenomenon, although psychiatrists have a positive attitude towards people with a mental health condition, they believe that mental care institutions reduce the living standards of neighboring areas. Other research shows that getting in touch with people with a mental health condition can shorten social distance (39). This study in Singapore also showed that if a medical professional has family members or close friends who have a mental illness, it will significantly reduce his social distance from the person with a mental health condition. A study in Japan in 2018 also showed that professional medical personnel has less prejudice about mental illness than the general public (40).

According to the data review and analysis article made in Taiwan in 2019, the problem of discrimination against people with a mental health condition has been improved considerably in Eastern or Western countries over the past 30 years. Medical education remains the vital key to improve this problem (41). The problem-based learning (PBL) teaching method has emerged in primary medical schools in recent years. It has become influential in teaching medical students and nursing students how to correctly treat patients with mental disorders and learn basic clinical skills to deal with mental illnesses (42).

Although there have been many studies before exploring whether medical staff has a different attitude towards the mentally ill from the general public, the research on medical staff's working years and their social distance to mental illness patients is still unclear and rare. To our best knowledge, it is the first study to investigate the impact of the length of service of health providers on the attitudes to mental illness in Taiwan. Moreover, utilizing online tools for data collection reduced efforts in data entry. There were some limitations in our study. Firstly, the study participants were recruited from one medical center and four clinics through convenience sampling. The sample might not represent all healthcare providers in Taiwan and was restricted to doctors, nurses, and allied health staff. Therefore, this would affect the generalizability of the study findings. Secondly, the cross-sectional design may not allow any casual relationships to be established. Thirdly, the modest response rate in our study, which introduced a potential response bias if the non-responders were systematically different from those who joined the survey. Lastly, the validity of the stigma measures in health care providers is too complicated due to the difficulty in 
choosing a gold standard.

\section{Conclusions}

The stigma of healthcare professionals with a shorter length of service was shown to have a relatively favorable attitude toward mentally ill people. Multiple regression analysis suggested that attitudes to mental illness among the health care provider were positively associated with younger age and higher education levels. For future studies, researchers could (I) use more representative samples; (II) explore how social contact affects attitudes to mental illness; (III) investigate the underlying mechanism of how age, education level, the married status might affect attitudes to mental illness. It was suggested that a good social contact experience with the patient, such as work and psychiatry training, is compelling. It implied that a systemic education program for caring psychiatric patients is necessary for Taiwan's health care institutions.

\section{Acknowledgments}

We thank Chuan-Yu Chen, Ph.D., and Hao-Min Cheng, M.D., Ph.D., for supervision.

Funding: None.

\section{Footnote}

Data Sharing Statement: Available at https://dx.doi. org/10.21037/ht-21-5

Conflicts of Interest: All authors have completed the ICMJE uniform disclosure form (available at https://dx.doi. org/10.21037/ht-21-5). WHC serves as the unpaid Editorin-Chief of Health Technology. The other authors have no conflicts of interest to declare.

Ethical Statement: The authors are accountable for all aspects of the work in ensuring that questions related to the accuracy or integrity of any part of the work are appropriately investigated and resolved. The present study was approved by the Joint Institutional Review Board (JIRB) of the Mackay Memorial Hospital (IRB numbers: 21MMHIS026e). The study was conducted in accordance with the Declaration of Helsinki (as revised in 2013). An explicit explanation was presented on the first page of the questionnaire. Entrance to the following pages was permitted after signing informed consent.
Open Access Statement: This is an Open Access article distributed in accordance with the Creative Commons Attribution-NonCommercial-NoDerivs 4.0 International License (CC BY-NC-ND 4.0), which permits the noncommercial replication and distribution of the article with the strict proviso that no changes or edits are made and the original work is properly cited (including links to both the formal publication through the relevant DOI and the license). See: https://creativecommons.org/licenses/by-nc-nd/4.0/.

\section{References}

1. Sartorius N, Gaebel W, Cleveland HR, et al. WPA guidance on how to combat stigmatization of psychiatry and psychiatrists. World Psychiatry 2010;9:131-44.

2. Hatzenbuehler ML, Phelan JC, Link BG. Stigma as a fundamental cause of population health inequalities. Am J Public Health 2013;103:813-21.

3. Corrigan PW, Markowitz FE, Watson AC. Structural levels of mental illness stigma and discrimination. Schizophr Bull 2004;30:481-91.

4. Rubin A, Babbie E.R. Empowerment series: Research methods for social work: Cengage Learning, 2016.

5. Rüsch N, Angermeyer MC, Corrigan PW. Mental illness stigma: concepts, consequences, and initiatives to reduce stigma. Eur Psychiatry 2005;20:529-39.

6. World Health Organization. Stigma and discrimination against the mentally ill in Europe. Briefing of the WHO European Ministerial Conference on Mental Health Facing the Challenges, Building Solutions: 12-15 January 2005. Helsinki, 2005.

7. Sartorius N. Fighting schizophrenia and its stigma. A new World Psychiatric Association educational programme. Br J Psychiatry 1997;170:297.

8. Henderson C, Robinson E, Evans-Lacko S, et al. Public knowledge, attitudes, social distance and reported contact regarding people with mental illness 2009-2015. Acta Psychiatr Scand 2016;134 Suppl 446:23-33.

9. Hansson L, Stjernswärd S, Svensson B. Changes in attitudes, intended behaviour, and mental health literacy in the Swedish population 2009-2014: an evaluation of a national antistigma programme. Acta Psychiatr Scand 2016;134 Suppl 446:71-9.

10. Robinson EJ, Henderson C. Public knowledge, attitudes, social distance and reporting contact with people with mental illness 2009-2017. Psychol Med 2019;49:2717-26.

11. Angermeyer MC, Matschinger H, Schomerus G. Attitudes towards psychiatric treatment and people with 
mental illness: changes over two decades. Br J Psychiatry 2013;203:146-51.

12. Mirnezami HF, Jacobsson L, Edin-Liljegren A. Changes in attitudes towards mental disorders and psychiatric treatment 1976-2014 in a Swedish population. Nord J Psychiatry 2016;70:38-44.

13. O'Reilly CL, Bell JS, Chen TF. Consumer-led mental health education for pharmacy students. Am J Pharm Educ 2010;74:167.

14. Rong Y, Glozier N, Luscombe GM, et al. Improving knowledge and attitudes towards depression: a controlled trial among Chinese medical students. BMC Psychiatry 2011;11:36.

15. Henderson C, Noblett J, Parke H, et al. Mental healthrelated stigma in health care and mental health-care settings. Lancet Psychiatry 2014;1:467-82.

16. Knaak S, Patten S, Ungar T. Mental illness stigma as a quality-of-care problem. Lancet Psychiatry 2015;2:863-4.

17. Pinfold V, Byrne P, Toulmin H. Challenging stigma and discrimination in communities: a focus group study identifying UK mental health service users' main campaign priorities. Int J Soc Psychiatry 2005;51:128-38.

18. González-Torres MA, Oraa R, Arístegui M, et al. Stigma and discrimination towards people with schizophrenia and their family members. A qualitative study with focus groups. Soc Psychiatry Psychiatr Epidemiol 2007;42:14-23.

19. Schulze B, Angermeyer MC. Subjective experiences of stigma. A focus group study of schizophrenic patients, their relatives and mental health professionals. Soc Sci Med 2003;56:299-312.

20. Corrigan PW, Druss BG, Perlick DA. The Impact of Mental Illness Stigma on Seeking and Participating in Mental Health Care. Psychol Sci Public Interest 2014;15:37-70.

21. Oexle N, Rüsch N, Viering S, et al. Self-stigma and suicidality: a longitudinal study. Eur Arch Psychiatry Clin Neurosci 2017;267:359-61.

22. Chekuri L, Mittal D, Ounpraseuth S. Relationship Between Stereotypes, Prejudice, and Social Distancing in a Sample of Health Care Providers. Prim Care Companion CNS Disord 2018;20:17m02264.

23. Yuan Q, Picco L, Chang S, et al. Attitudes to mental illness among mental health professionals in Singapore and comparisons with the general population. PLoS One 2017;12:e0187593.

24. Seaton V, Piel M. Student pharmacists' social distancing toward people with mental illness. Ment Health Clin 2018;7:181-6.
25. Yuan Q, Abdin E, Picco L, et al. Attitudes to Mental Illness and Its Demographic Correlates among General Population in Singapore. PLoS One 2016;11:e0167297.

26. Shruti A, Singh S, Kataria D. Knowledge, attitude and social distance practices of young undergraduates towards mental illness in India: A comparative analysis. Asian J Psychiatr 2016;23:64-9.

27. Kopera M, Suszek H, Bonar E, et al. Evaluating Explicit and Implicit Stigma of Mental Illness in Mental Health Professionals and Medical Students. Community Ment Health J 2015;51:628-34.

28. Aydin N, Yigit A, Inandi T, et al. Attitudes of hospital staff toward mentally ill patients in a teaching hospital, Turkey. Int J Soc Psychiatry 2003;49:17-26.

29. Grausgruber A, Meise U, Katschnig H, et al. Patterns of social distance towards people suffering from schizophrenia in Austria: a comparison between the general public, relatives and mental health staff. Acta Psychiatr Scand 2007;115:310-9.

30. Thornicroft G, Mehta N, Clement S, et al. Evidence for effective interventions to reduce mental-health-related stigma and discrimination. Lancet 2016;387:1123-32.

31. Knaak S, Mantler E, Szeto A. Mental illness-related stigma in healthcare: Barriers to access and care and evidencebased solutions. Healthc Manage Forum 2017;30:111-6.

32. Lyons $Z$. Attitudes of medical students toward psychiatry and psychiatry as a career: a systematic review. Acad Psychiatry 2013;37:150-7.

33. Manschreck TC, Kleinman AM. Psychiatry's identity crisis: a critical rational remedy. Gen Hosp Psychiatry 1979;1:166-73.

34. Katschnig H. Are psychiatrists an endangered species? Observations on internal and external challenges to the profession. World Psychiatry 2010;9:21-8.

35. Mårtensson G, Jacobsson JW, Engström M. Mental health nursing staff's attitudes towards mental illness: an analysis of related factors. J Psychiatr Ment Health Nurs 2014;21:782-8.

36. Lauber C, Anthony M, Ajdacic-Gross V, et al. What about psychiatrists' attitude to mentally ill people? Eur Psychiatry 2004;19:423-7.

37. Wahl O, Aroesty-Cohen E. Attitudes of mental health professionals about mental illness: a review of the recent literature. J Community Psychol 2010;38:49-62.

38. Stuber JP, Rocha A, Christian A, et al. Conceptions of mental illness: attitudes of mental health professionals and the general public. Psychiatr Serv 2014;65:490-7.

39. Subramaniam M, Abdin E, Picco L, et al. Stigma towards 
people with mental disorders and its components - a perspective from multi-ethnic Singapore. Epidemiol Psychiatr Sci 2017;26:371-82.

40. Fujii T, Hanya M, Kishi M, et al. An internet-based survey in Japan concerning social distance and stigmatization toward the mentally ill among doctors, nurses, pharmacists, and the general public. Asian J Psychiatr 2018;36:1-7.

\section{doi: $10.21037 / \mathrm{ht}-21-5$}

Cite this article as: Wong $\mathrm{CH}$, Chien SC, Zeng YH, Huang CC, Tsai W, Chen CW, Su YJ, Chang WH, Chen PY. Influence of social distance toward individuals with psychotic disorders by medical background. Health Technol 2021;5:12.
41. Lien YY, Lin HS, Tsai CH, et al. Changes in Attitudes toward Mental Illness in Healthcare Professionals and Students. Int J Environ Res Public Health 2019;16:4655.

42. Cooper C, Carver N. Problem based learning in mental health nursing: the students' experience. Int J Ment Health Nurs 2012;21:175-83. 